\title{
Lectura en voz alta y narración en lenguas indígenas
}

\section{Reading aloud and indigenous languages narrative}

\section{Lorena Córdova-Hernández ${ }^{1}$}

Fecha de recepción: 21 de marzo de 2019

Fecha de aceptación: 28 de agosto de 2019

\begin{abstract}
Resumen - Este artículo describe algunas experiencias obtenidas en el Taller de lectura en voz alta para la región zapoteca de Yautepec, Oaxaca, en 2017. El objetivo consistió en apoyar a un grupo de docentes del nivel de educación indígena con la socialización de la técnica de lectura en voz alta en lengua dizdea (zapoteco); en específico, utilizar este tipo de lectura como medio para desarrollar lectura transaccional y reactivar la narración en lenguas indígenas que se encuentran en riesgo de desaparición. En la descripción aquí vertida se retoman tres ejes: escritura, lectura y narración oral, los cuales se consideran elementos indisociables -aunque no los únicos- en la promoción y revitalización de las lenguas indígenas desde los soportes escritos o alfabéticos.
\end{abstract}

\section{Palabras clave:}

Lectura en voz alta, lectura transaccional, narración oral, revitalización lingüística.
Abstract - This paper describes some experiences obtained in the Reading Aloud Workshop for the Zapotec region of Yautepec, Oaxaca (2017), whose goal was to support an indigenous education teachers group with the socialization of the reading aloud technique in dizdea language (Zapotec). Specifically, the use of this literary practice to develop transactional reading and to reactivate the oral storytelling tradition in endangered indigenous languages. The description presents three axes: writing, reading and oral storytelling, which are considered integral elements -but not the only onesin the promotion and revitalization of indigenous languages from written or alphabetic supports.

\section{Keywords:}

Reading aloud, transactional reading, oral narrative, language revitalization. 


\section{Introducción}

n 2016, un grupo interinstitucional de investigadores, docentes y funcionarios públicos se dieron a la tarea de impartir el Taller de lectura en voz alta para la región zapoteca de Yautepec, Oaxaca, ${ }^{2}$ con el objetivo general de capacitar a docentes bilingües de educación indígena en la técnica de "lectura en voz alta" en dizdea (zapoteco). Es decir, el propósito fue, "por un lado, preparar al docente en el dominio de sus dos lenguas en uso y, por el otro, abordar la alfabetización desde la lectura literaria en situación de lenguas en contacto" (Vergara, 2017, s/p).

El presente texto describe las experiencias en torno a la lectura en voz alta como herramienta de lectura transaccional (Rosenblatt, 1988; Vergara, 2017) y la reactivación de la narración en lenguas indígenas en situación de riesgo (Córdova, 2016; Córdova 2019). Para ello es importante transmitir el interés por generar una discusión dialógica entre la escritura, la lectura y la narración con la finalidad de motivar la (re)utilización de la lengua, en este caso zapoteco y chontal. A partir de ello, se busca propiciar un nuevo uso de la lectura en voz alta, no sólo como instrumento de promoción literaria o de enseñanza, sino como una herramienta multimodal.

El ideal de este tipo de acciones es favorecer la revitalización del dizdea en San Bartolo Yautepec y, de manera indirecta, de la variante lingüística chontal de la Sierra del estado de Oaxaca. En los casos zapoteco y chontal que aquí se describirán, el nivel de desplazamiento lingüístico frente al español es alto. Sin embargo, en este contexto, el dizdea de Yautepec se encuentra en elevado riesgo de desaparecer, por lo que la necesidad de diseñar propuestas para la reversión de tal situación es innegable.

\section{Contexto}

El Taller de lectura en voz alta para la región zapoteca de Yautepec fue coordinado por la Mtra. Judith Vergara Monreal, de la Universidad Pedagógica Nacional (Xalapa), y facilitado por el equipo interinstitucional en San Bartolo Yautepec, Oaxaca, a lo largo de dos días en el mes de mayo de 2017. Como se mencionó líneas antes, estuvo dirigido a profesores de educación indígena (de los niveles preescolar y primaria) de la Jefatura de Zonas de Supervisión de Educación Indígena No. 14, Santa María Ecatepec (Yautepec), Oaxaca, así como a promotores comunitarios del dizdea. No obstante, las comunidades que atiende esta Jefatura no sólo son zapotecas, sino también de origen chontal, por lo que en cualquier taller participan profesores de ambas regiones, aunque los promotores sólo fueron hablantes de dizdea.

El dizdea de Yautepec es una variante lingüística en alto peligro de desaparición. A pesar de encontrarse geográficamente cerca de los hablantes del zapoteco del Istmo de Tehuantepec, sólo cuenta con pocos hablantes adultos 0 ancianos. ${ }^{3}$ Investigadores e instituciones federales han creado materiales didácticos y/o de consumo comunitario para revertir el proceso de desplazamiento de esta lengua. Por ejemplo:

[Una] lotería y memorama. Material elaborado por Adela Covarrubias Acosta (2013). [Un] Dominó. Diseñado y elaborado por Carlos López Villaseñor (ENAH [Escuela Nacional de Antropología e Historia], 2010; demo sin publicar). Figuras para colorear (elaboración de una colección de figuras por Sandra Hernández Cantú, 2010, sin publicar). Yaak, Vocabulario Dizdea en Línea, elaborado por Zobeida Sánchez

2 El Instituto Nacional de Lenguas Indígenas (INALI), la UABJO, la UPN (Xalapa), el Centro de Estudios y Desarrollo de las Lenguas Indígenas de Oaxaca (CEDELIO) y la Universidad Estatal de California en Los Ángeles integraron el equipo interinstitucional.

${ }^{3}$ Es importante mencionar que existe una idea generalizada de que el zapoteco del Istmo tiene alta vitalidad, siendo la ciudad de Juchitán uno de los lugares que se reconoce con ese vigor; pero incluso en esta localidad el desplazamiento es acelerado. 
Bonilla, auspiciado por el Inali y asesorado por la UAQ [Universidad Autónoma de Querétaro]. Xkech dizdea. Libro zapoteco (Coordinado por Rosa María Rojas Torres, [auspiciado por] Inali, 2013). [Asimismo,] señalética en lengua [2014 y] Mural comunitario [2014] (Rojas \& Sánchez, 2016, s/p).

Estas acciones fueron continuidad del programa de inmersión total "Nido de lenguas", en el que un grupo de hablantes y el INALI se organizaron para que los niños comenzaran a aprender zapoteco, en 2012. Incluso, se edificó "la casa del zapoteco", una construcción tradicional de adobe y palma para poder llevar a cabo las actividades. ${ }^{4}$ Asimismo, en la Jefatura de Zonas de Supervisión ya habían emprendido algunas clases de lengua. De esta manera, se pueden observar más de una década de diferentes esfuerzos para tratar de revertir el desplazamiento del zapoteco de Yautepec. Sin embargo, poco a poco estas iniciativas se han convertido en procesos aislados y, en algunos casos, se han dejado de realizar completamente, como es el caso de Nido de lenguas. Ante esta situación, el desplazamiento sigue su curso y se ha hecho necesario no dejar de hacer pequeñas acciones para revitalizar el dizdea.

En 2016, el Asesor Técnico Lingüístico (ATL) de la Jefatura de Zonas de Supervisión No. 14 que atendía a la región zapoteca se acercó al equipo interinstitucional para solicitar un taller sobre escritura del zapoteco pues, en general, se tiene la idea de que la lengua se revitalizará a partir de escribirla y de producir materiales escritos. Un año antes, en la misma Jefatura, el equipo interinstitucional impartió un taller sobre enseñanza de la lengua chontal como segunda lengua; asimismo, en 2016, el taller sobre escritura de textos funcionales en chontal. Por tal motivo, para el ATL y las autoridades administrativas de la Jefatura de
Zonas fue importante atender a la región zapoteca, por lo que las tareas a realizar se calendarizaron para el año 2017.

Como se dijo líneas arriba, interinstitucionalmente el proyecto del taller se desarrolló para el caso del dizdea. Sin embargo, debido a la desubicación lingüística, algunos profesores chontales atienden comunidades zapotecas o a la inversa, por lo que en el resto del texto se hará referencia a ambas lenguas, aunque el foco de atención del taller fue, principalmente, la lectura en voz alta en dizdea. En este contexto, la mayoría de los profesores no son hablantes de la lengua zapoteca, por lo que escribir en lengua indígena que ya no se habla o no se conoce implica un doble reto.

\section{Desarrollo de la propuesta de taller}

En el campo de la revitalización de lenguas, la puesta en marcha de metodologías o acciones a favor de la promoción, uso y desarrollo de las lenguas indígenas es bienvenido. Empero, en el caso de lenguas o variedades con alto riesgo de desaparición, estas acciones deben ser repensadas a la luz de las actividades que se han iniciado con anterioridad. Es decir, se debe reflexionar cuál ha sido el impacto de acciones previas y valorar si es pertinente seguir en la misma línea o redireccionarlas (Córdova, 2019). En el caso del dizdea y del chontal que aquí se describirán, se han emprendido varias acciones, de las cuales la mayoría ha sido material escrito. No obstante, este material tiene circulación reducida y su consumo es más académico o escolar que comunitario, por lo que el proceso de revitalización es nulo.

El equipo interinstitucional recibió la propuesta de la Jefatura de Zonas para estructurar un taller de escritura de zapoteco y durante el segundo semestre de 2016 se dedicó a organizar los contenidos y el objetivo. Algunas de las premisas de las que se

${ }^{4}$ Para observar más a detalle la construcción, véase el video Casa tradicional, disponible en https://www.youtube.com/watch?v=RCjwrDIUbeM 
partieron fueron las siguientes: en primer lugar, desarrollar un taller que se volviera un diálogo de saberes entre promotores o hablantes del dizdea y profesores; es decir, el taller como pretexto para abrir un diálogo que muchas veces es invisibilizado debido al desplazamiento de los saberes comunitarios por los saberes escolares. En segundo lugar, impartir un taller que pudiera mostrar las virtudes de la escritura de una lengua en procesos revitalizadores, en tanto que el ejercicio escritural tenga como objetivo comunicarse en la lengua indígena; esto es, utilizar el soporte escrito para reintegrar a la lengua a la interacción cotidiana de los hablantes. Por último, y no menos importante, cumplir con las expectativas de profesores y promotores de producir escritos en zapoteco.

Al igual que en el caso chontal, se esperaba que los promotores zapotecos tuvieran una mayor participación, por lo que el papel de los profesores sería más como facilitadores de la escritura. Entonces, no se podía pensar en la redacción de textos largos, sino cortos que pudieran ser fácilmente transcritos y, por ende, más fáciles de leer. Aunado a ello, la experiencia chontal de 2016 mostró que tanto docentes como promotores tienen poca práctica lectora. Si bien están alfabetizados en español, sus prácticas lectoras son reducidas. Es decir, el soporte escrito se utiliza mínimamente como medio comunicativo; aunque varios promotores y profesores ahora se comunican por mensajería electrónica, las dinámicas comunitarias e incluso escolares siguen siendo con poco soporte escrito. En ese sentido, se tenía que dotar a los asistentes de herramientas y ánimo para revitalizar, escribir y leer el dizdea. Por ello, la apuesta fue generar, en la medida de lo posible, estrategias interdisciplinarias que comenzaran a incidir en la revitalización del zapoteco y en su desarrollo en soportes escritos.

A partir de lo anterior, el equipo interdisciplinario tenía experiencia en procesos de revitalización, pero no necesariamente en facilitar dinámicas de lectura en voz alta. Por lo tanto, se requirió de la asesoría de Judith Vergara, de la Universidad Pedagógica Nacional, para armar la propuesta del taller, pues no sólo se trataba de hacer referencia a la importancia del zapoteco y la necesidad de proponer acciones comunitarias, sino de brindar metodologías para un ejercicio lector que motivara el uso de la lengua escrita y oral.

\section{Leer}

El objetivo revitalizador del taller fue que, ya fuera mediante el soporte oral o escrito, los participantes se motivaran a transmitir, utilizar o aprender la lengua zapoteca y, en su caso, el chontal. En ese sentido, la lectura en voz alta se convertía en la mejor aliada, pues además de que le brinda prestigio a la lengua a partir del escrito, permite volver a escuchar lenguas que poco a poco se están quedando dormidas. Así, esta actividad evidencia la necesidad de generar materiales para su lectura y, a su vez, le otorga nuevamente voz o el poder de la palabra a los hablantes.

El equipo revitalizador partió de la idea de que la lectura en voz alta, para cumplir con sus objetivos revitalizadores, debe tener un enfoque comunicativo y funcional. Es decir:

\begin{abstract}
la lectura en voz alta es una actividad social que permite a través de la entonación, pronunciación, dicción, fluidez, ritmo y volumen de la voz darle vida y significado a un texto escrito para que la persona que escuche pueda soñar, imaginar o exteriorizar sus emociones y sentimientos (Cova, 2004, p. 55).
\end{abstract}

Así, al dotar de herramientas para esta práctica, los promotores y profesores pueden comenzar a reivindicar no sólo la lengua como sistema lingüístico, sino los sistemas de significación que en ella se encuentran codificados.

El ejercicio lector en formatos largos y diversos de promotores y profesores, por lo general, es reducido. Si partimos de la idea de que comúnmente la lectura 
es tomada como sinónimo de alfabetización, en las comunidades indígenas la alfabetización es el objetivo por alcanzar, no el desarrollo del objetivo lector. En ese sentido, los acercamientos de los promotores culturales y de los profesores de nivel indígena hacia la lectura, y la lectura en voz alta, sobre todo en español, ha sido poco productiva en términos de apropiación del hábito lector y la práctica de la lengua indígena (Córdova, 2016).

Para Daniel Cassany (2007), la costumbre escolar de la lectura en voz alta en español, incluso para niños cuya primera lengua es este idioma, resulta una suerte de "crueldad infantil", pues se coloca al pequeño frente a una audiencia sin una formación previa en lectura de textos en general y lectura de voz alta en particular. De esta manera, se puede afirmar que para los hablantes de lenguas distintas al español, la lectura y especialmente en voz alta en español, sin herramientas de lectura previas, es y seguirá siendo una especie de castigo.

Por tal motivo, en la planeación y ejecución del taller se diseñaron estrategias de lectura en voz alta que permitieran un ejercicio de "lectura transaccional", a través de la didáctica de la lectura.

Cada acto de lectura es un evento, una transacción que involucra a un lector en particular y una configuración particular de marcas en una página, y que ocurre en un momento particular en un contexto particular. Ciertos estancamientos organísmicos, ciertos rangos de sentimiento, ciertos enlaces verbales o simbólicos, se agitan en el depósito lingüístico. A partir de estas áreas activadas, para expresarlo de manera más simple, la atención selectiva -condicionada por múltiples factores personales y sociales que entran en la situaciónselecciona elementos que se sintetizan o se fusionan con lo que constituye el "significado". El "significado" no reside ya hecho en el texto o en el lector, sino que ocurre durante la transacción entre el lector y el texto (Rosenblatt, 1988, p. 4).

A partir de la lectura transaccional se desarrollan aspectos lingüísticos y sociales pertinentes para la revitalización. El desplazamiento lingüístico se materializa en el reemplazo de una lengua por otra; sin embargo, no es un suceso meramente lingüístico sino también social, donde se pierden el sistema comunicativo y los "significados culturales". Al reactivar la lectura por medio del texto y un lector formado, la transacción permitirá recobrar esos significados culturales.

En la actualidad nadie puede negar los beneficios cognitivos, sociales y terapéuticos de la lectura, y en el caso de la revitalización estos beneficios potencializan sobremanera los procesos a favor de las lenguas. Pero el provecho más grande, y en eso la lectura en voz alta es el mejor aliado, radica en que es un ejercicio que por medio de la práctica y el disfrute puede dejar de ser meramente escolar y puede llevarse al ámbito comunitario y familiar. Si bien existen varios ejercicios a nivel mundial en torno a la lectura en voz alta en lenguas indígenas, muchos de ellos son audiolibros que sólo registran palabras y no historias completas. Por ejemplo, algunos talking books se han publicado en Australia para la lengua gurindji. ${ }^{5}$ En Canadá se ha creado un sitio en internet para la lengua tutchone del sur en el territorio de Yukón, en el que han publicado algunas historias en lengua, pero no ejercicios de lectura en voz alta. ${ }^{6}$ En México, José Antonio Flores Farfán ha desarrollado audiolibros que revalorizan algunos repertorios discursivos (adivinanzas, historias de creación, etcétera) del maya yucateco, así como

\footnotetext{
${ }^{5}$ Véase https://www.uq.edu.au/news/article/2015/06/talking-book-gives-new-voice-indigenous-languages

${ }^{6}$ Véase http://www.macleans.ca/culture/books/how-to-preserve-indigenous-languages-for-the-next-generation/
} 
del náhuatl, mixteco, otomí, entre otras lenguas, que motivan al fomento del (re)uso de la lengua a partir del soporte escrito (Flores, 2015).

En 2011, José Antonio Flores Farfán, Diego Pérez Hernández, Lorena Córdova y Judith Vergara, además de otros colaboradores, participaron en la producción del audiolibro Yaljub'al atz'am atz'am t'a San Mateo/ La historia de la sal de San Mateo (2012) en versión bilingüe chuj-español, sobre la historia del origen de las minas de sal del pueblo chuj en San Mateo Ixtatán, Guatemala, con el objetivo de revitalizar el chuj en Chiapas, en la zona de los Lagos de Montebello. Durante la elaboración, Vergara y Córdova se dieron cuenta de un aspecto importante: las personas interesadas en la revitalización que son hablantes de la lengua objetivo pueden participar; sin embargo, aunque sean hablantes, les cuesta mucho trabajo hacer lectura en voz alta frente a un micrófono. En el caso de este audiolibro, aunque se tenía la historia traducida y editada, así como las respectivas ilustraciones, hicieron falta mediadores de lectura chuj que pudieran dar voz a los personajes. Si bien se contó con la participación de tres hablantes, el audio es plano, no tiene juego de voz o de dicción, pues no se contaba con las herramientas de lectura en voz alta.

Con este telón de fondo, el equipo interinstitucional puso en marcha el taller para el caso del dizdea. Siendo el primero en su tipo, no por el hecho de que los profesores y promotores no hayan impartido talleres previos sobre escritura y lectura en lengua indígena, sino porque no habían tomado un curso sobre lectura transaccional en voz alta para revitalizar la lengua.

\section{Escribir}

En el campo de las lenguas indígenas, tanto en el ámbito académico, activista y burocrático, el ejercicio de escribir una lengua es sinónimo de desarrollarla. En el caso de México, la búsqueda del INALI por la normalización o institucionalización de las lenguas indígenas es una meta que tiene desde su creación y que, en esta última administración (2019), se ha priorizado por encima de los proyectos comunitarios de revitalización que intentan revalorizar a las lenguas desde múltiples soportes. En el caso de Oaxaca, desde hace más de cinco décadas la escritura de las lenguas indígenas forma parte de las luchas de los movimientos indígenas.

[...] En los últimos diez años se ha generado en el estado una serie de movimientos que propugnan por la afirmación y conservación de las lenguas indígenas. Dentro de las estrategias propuestas por estos grupos, el logro de la escritura de los idiomas indígenas ha jugado un papel central. En todos estos proyectos la apropiación de la escritura es concebida como un mecanismo de afirmación, revalorización y desarrollo de las lenguas indígenas. Esta intención se ha visto reflejada en una dinámica más ágil, durante las reuniones para la unificación de los alfabetos prácticos, y en la capacidad, de la mayoría de los grupos, de trascender los problemas sectoriales a nivel regional y establecer una propuesta de alfabeto único para toda la etnia o para toda la región. La voluntad de apropiación de la escritura como estrategia de afirmación y cohesión étnica ha supuesto concebir a la lengua en su conjunto y a la escritura como un medio de unificación de las variantes regionales (Pardo, 1993, pp. 109-110).

A pesar de los recursos invertidos en desarrollar alfabetos, la escritura de lenguas indígenas en el estado aún es reducida. Prácticamente no existe un lugar o región en donde una lengua indígena, en el soporte escrito, sea vehículo de comunicación pleno. Incluso, en la zona mixe o ayuuk, el zapoteco del Istmo o el mixteco (este último cuenta con una academia 
interestatal en la que convergen mixtecos de tres entidades federativas) aún no alcanzan un uso extendido de la escritura. Asimismo, en todos los intentos por unificar los alfabetos surgen disputas, y más de las que se piensa.

Con todo, escribir una lengua, al ser una tarea que se ha popularizado como individual, es un ejercicio en el que se puede encontrar gente especializada. Es decir, existen tanto promotores como profesores y lingüistas que escriben las lenguas indígenas. Sin embargo, al ser ejercicios individuales, pocas veces pasan por procesos de validación comunitaria, lo cual llega a propiciar poco consumo local o rechazo de los materiales escritos que se generan.

En el caso del taller de lectura en voz alta, se extendió la invitación a escribir y para los organizadores no hay mejor método que este tipo de lectura para validar los escritos, pues es por la vía de la oralidad que muchos de los asistentes pueden evaluar la inteligibilidad de los textos. Asimismo, es un proceso inicial que no se restringe al uso o a la búsqueda de las grafías correctas, al contrario, se utilizan algunas que permiten transmitir la fuerza ilocutiva de la lengua y los significados culturales ahí descritos. Esto permitió que los lectores pudieran escribir sus historias sin temor a que sus textos fueran evaluados ortográficamente. Al contrario, su interés se centró en transmitir el mensaje y significados que la lectura transaccional permite comunicar.

Los textos que se produjeron, en primera instancia, fueron cortos. Sin embargo, los asistentes escribieron textos de una cuartilla, lo cual es síntoma de la confianza que adquirieron al saber que su escrito no sería revisado en términos de la gramática. En el caso de los asistentes que no hablaban una lengua indígena, realizaron la dinámica en español, pero ejercitando su práctica de lectura en voz alta. El principio básico era escribir, no importando la lengua. Es decir, lo relevante era escribir para leer y leer para revitalizar.

\section{Narración oral}

La escritura de textos se torna estéril si no hay quien los lea. En ese sentido, en el campo de la revitalización el hecho de generar material que no sea utilizado por las comunidades de hablantes o aprendices tiene un efecto nulo. Así, la idea de producir textos para ser leídos y transmitidos a un público u oyentes del dizdea y del chontal incentivaba su consumo y de seguir con este ejercicio postaller, los asistentes podrían apropiarse de la escritura y lectura de dichas lenguas, cumpliendo así con algunas de las metas comunicativas que se tienen para su uso.

La lectura de los textos generados estuvo antecedida por una sesión de cinco horas en la que se llevaron a cabo actividades o ejercicios en torno a la técnica de lectura en voz alta, sugeridos por Judith Vergara, sobre dicción, ritmo, velocidad, volumen, énfasis, movimientos faciales y corporales, etcétera. Posteriormente se brindaron elementos mínimos para seleccionar o escribir un relato o cuento, tomando en cuenta su brevedad, sentimientos, cuidando un lenguaje inteligible. Si bien en una sesión no se lograrían agotar tanto los ejercicios como el surgimiento de dudas, lo que es un hecho es que estos ejercicios permitieron la integración del grupo de asistentes, infundir confianza tanto en su lectura como escritura y crear relatos emergentes en la lengua indígena.

Como se dijo, el objetivo fue que entre los participantes se encontraran tanto profesores de educación indígena como promotores de la lengua. Sin embargo, aunque sí se contó con la presencia de un promotor de dizdea, no quiso integrarse en las actividades; al contrario, su "participación" fue, en este sentido, liminal. Por su parte, aunque en el taller había profesores chontales, no asistieron promotores chontales. De esta manera, la reducida asistencia de los promotores transmitió la idea de que probablemente los textos que se produjeran y leyeran serían en español; aun así, se escribieron algunos en chontal y un par en zapoteco. 
Si bien en este taller se tenía claro que no se generarían muchos textos en lengua indígena, el hecho de leer textos sobre algunos aspectos de la comunidad comenzó a activar la memoria lingüística y cultural de los asistentes, un elemento trascendental en la revitalización de lenguas con alto riesgo de desaparición. Así, la lectura en voz alta no sólo permitía reivindicar el sistema de sonidos que poco a poco deja de desaparecer en las comunidades zapotecas y chontales, sino que hace posible remembrar historias tanto de la propia tradición oral como de episodios que los autores-lectores recuerdan.

El ejercicio llevado a cabo en el taller descentralizó los soportes en los que normalmente la lectura se ha promovido; tanto promotores como autores pudieron leer y escribir en hojas sueltas o en sus cuadernos. Es decir, no necesitaron "libros" de autores reconocidos para poder leer, sólo hacía falta que se asumieran como escritores y lectores de microrrelatos que transmitieran un mensaje con significados locales, inteligibles para los escuchas $y$, sobre todo, cargados de una memoria cultural vigente que si bien puede estar dormida, necesita ser activada y reivindicada para volver a estar presente en espacios formales y no formales de las comunidades. De esta manera, la lectura en voz alta no sólo brinda cierto placer o goce estético, también permite volver a dar espacio a esas voces que, desde hace varios siglos, han querido ser silenciadas.

\section{Conclusiones}

El lingüista Frank Seifart menciona que quien es escritor no necesariamente es lector y que un lector no necesariamente es un escritor. En el caso de las lenguas indígenas con alto riesgo de desaparición yo agregaría que quien es hablante pleno de una de ellas no necesariamente es lector, escritor o traductor de la misma. En ese sentido, la complejidad es más amplia, pues no se cuenta con los recursos humanos suficientes para integrar grupos de personas que desarrollen cada una de esas competencias. Al contrario, muchas veces quien es hablante ejercita todas las habilidades; en contraparte, muchos hablantes no logran ninguna de ellas.

A partir de lo anterior, para que la lectura en voz alta se convierta en una estrategia revitalizadora se necesita comenzar a formar a más personas, ya sea como lectoras, escritoras o escuchas, pues cada día los recursos humanos se van agotando. Asimismo, es necesario sistematizar los procesos de formación lectora en el campo de las lenguas indígenas y seguir diversificando los soportes y espacios de práctica. Para que el dizdea sea revitalizado se necesitan cambiar muchas condiciones sociolingüísticas que motivan su desplazamiento; sin embargo, comenzar con pequeños registros escritos para su lectura en voz alta puede contribuir a empezar a revertir este desplazamiento y otorgarle un nuevo estatus. No para brindarle el status quo del español, sino para otorgarle un (re)uso indispensable que la reactive en el ámbito social, lo cual es el objetivo central en el campo de la revitalización de lenguas en alto riesgo de desaparición.

\section{Referencias}

Cassany, D. (2007). Luces y sombras de la lectura en voz alta. Peonza: Revista de literatura infantil y juvenil, 82, 21-32.

Córdova, L. (2016). Consumo literario en lenguas indígenas: experiencias de revitalización desde el Sur de México. Revista CS, 18, 37-61. DOI http:// dx.doi.org/10.18046/recs.i18.2053

Córdova, L. (2019). Metáforas ecológicas, ideologías y políticas lingüísticas en la revitalización de lenguas indígenas. México: Universidad Autónoma "Benito Juárez" de Oaxaca-Conacyt.

Cova, Y. (2004). La práctica de la lectura en voz alta en el hogar y en la escuela a favor de niños y niñas. Sapiens. Revista Universitaria de Investigación, 5(2), 53-66. 
Flores Farfán, J. A. (2015). Na'at le ba'ala'paalen Na'at le ba'ala'paalen. Adivina esta cosa ninio. La experiencia de revitalización, mantenimiento y desarrollo lingüístico y cultural en México con énfasis en el maya yucateco. Trace, 67, 92-120.

Flores Farfán, J. A., Córdova Hernández, L., Pérez Hernández, D. \& Vergara, J. (2012). Yaljub'al atz'am atz'am t'a San Mateo/La historia de la sal de San Mateo. México: Conacyt/CIESAS/Linguapax/Unesco Cataluña/Innovación y Apoyo Educativo A.C.

Pardo, M. T. (1993). El desarrollo de la escritura de las lenguas indígenas de Oaxaca. Revista Iztapalapa, 29, 109-134.
Rojas, R. M. \& Sánchez, Z. (2016). Mnech Dizdea. El desplazamiento de la lengua de los bartoleños. Ponencia presentada en el $7^{\circ}$ Coloquio sobre Lenguas Otomangues y Vecinas, 7-10 de abril, Oaxaca, Oax.

Rosenblatt, L. (1988). Writing and Reading: The Transactional Theory. Nueva York: New York University.

Vergara, J. (2017). Taller de lectura en voz alta (Manuscrito en preparación).

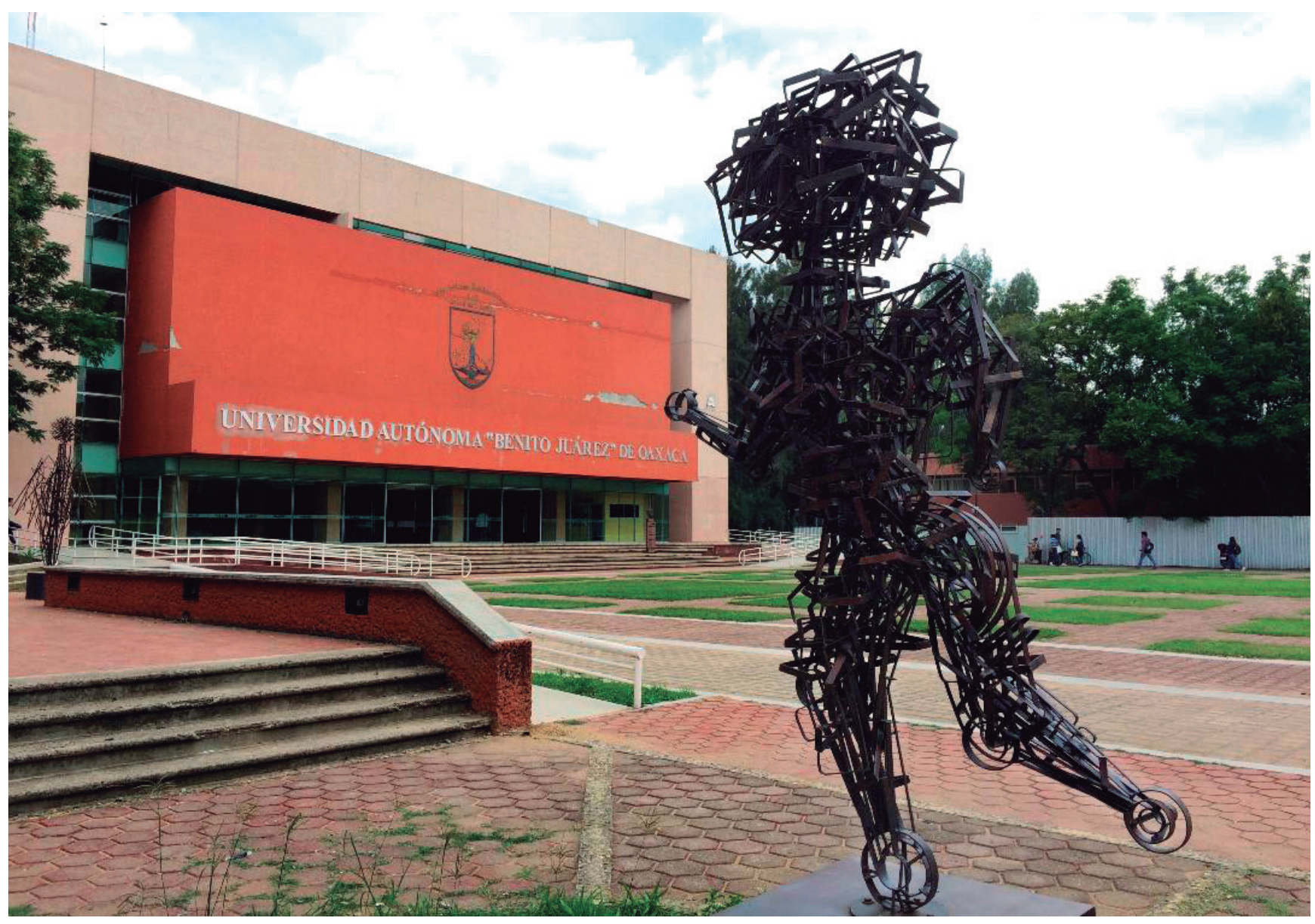

"La corredora" | Metal sobre base de acero | 2.81 m x 1.42 m x 60 cm I 2019 


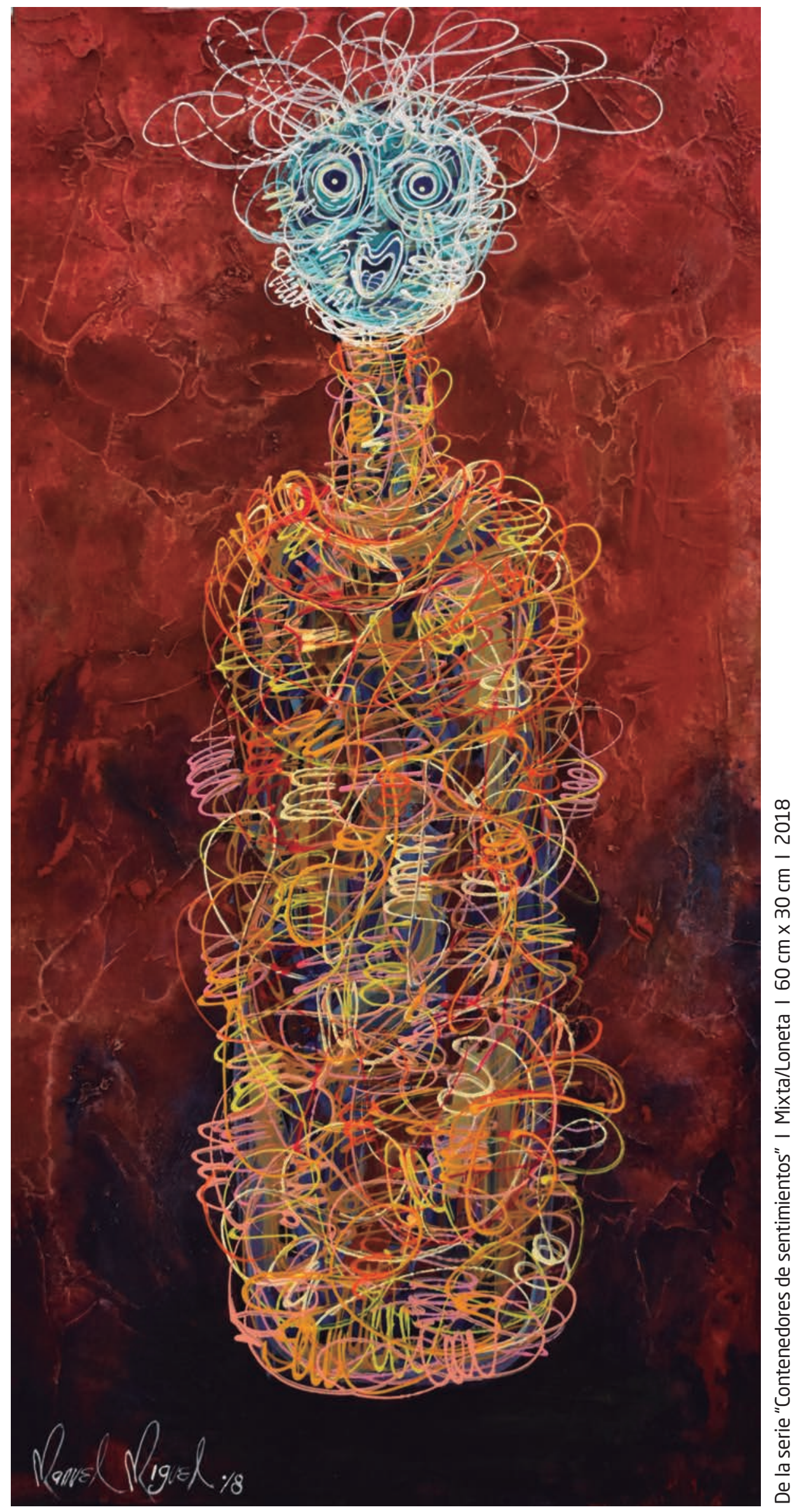

Tequio, enero-abril 2020, vol. 3, no. 8 


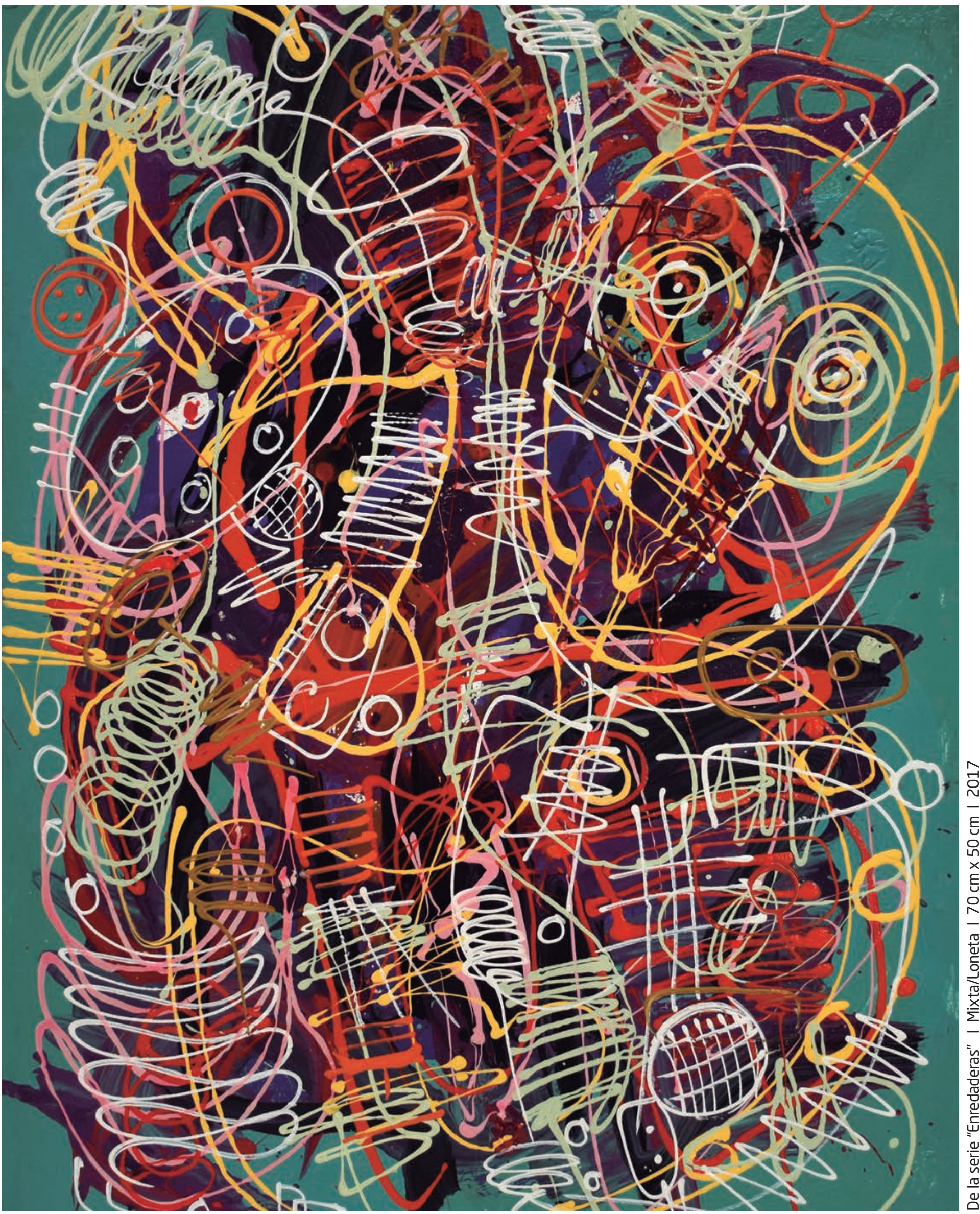

